\title{
Oceanography
}

CITATION

Carter, G.S., O.B. Fringer, and E.D. Zaron. 2012. Regional models of internal tides.

Oceanography 25(2):56-65, http://dx.doi.org/10.5670/oceanog.2012.42.

$\mathrm{DOI}$

http://dx.doi.org/10.5670/oceanog.2012.42

COPYRIGHT

This article has been published in Oceanography, Volume 25, Number 2, a quarterly journal of The Oceanography Society. Copyright 2012 by The Oceanography Society. All rights reserved.

USAGE

Permission is granted to copy this article for use in teaching and research. Republication, systematic reproduction, or collective redistribution of any portion of this article by photocopy machine, reposting, or other means is permitted only with the approval of The Oceanography Society. Send all correspondence to: info@tos.org or The Oceanography Society, PO Box 1931, Rockville, MD 20849-1931, USA. 


\section{REGIONAL MODELS OF INTERNAL TIDES}

BY GLENN S. CARTER, OLIVER B. FRINGER, AND EDWARD D. ZARON

ABSTRACT. Internal tides are ubiquitous in the ocean, and they play an important role in a range of ocean processes, for example, particle dispersal, acoustics, and vertical buoyancy flux. The wavelength of internal tides can be as much as $250 \mathrm{~km}$ in the open ocean, but as the generation of these tides depends on the angle between the depth-averaged current and the topography, there can be considerable local spatial variability. This range of scales makes it difficult to develop a comprehensive understanding of the processes involved from observations alone. Regional numerical modeling provides a way to study the generation and early propagation of internal tides at high resolution. Here, we review the role that regional internal tide models, primarily hydrostatic models, can play in increasing our understanding.

\section{INTRODUCTION}

Internal tides are simply internal gravity waves with tidal frequencies. Most people are familiar with the phenomenon of tides as expressed in the twicedaily vertical oscillation of sea level along the coast. However, these vertical oscillations arise from the propagation of surface, or barotropic, shallow-water waves (i.e., waves in which the wavelength is much longer than the depth) that contain both vertical (which gives rise to the easily observed surface oscillations) and horizontal motion. When the horizontal tidal currents encounter an underwater obstacle, such as a submarine ridge, the water is forced up and over the obstacle. If the water column is stratified, then the water being pushed up one side of the obstacle elevates the isopycnals (surfaces of constant density), whereas the water descending on the other side depresses them. Near the obstacle, the isopycnals are forced to oscillate with tidal frequency, leading to disturbances of the isopycnals that propagate away as internal gravity waves, or internal tides. Because the isopycnal disturbances deviate from nearly level, isobaric surfaces, disturbances in the velocity and pressure fields arising from internal gravity waves are referred to as "baroclinic," and the radiating waves are sometimes known as baroclinic tides to differentiate them from the barotropic, or surface tides. Internal tides propagate at roughly 2-3 $\mathrm{m} \mathrm{s}^{-1}$, about 100 times slower than barotropic tides. The restoring force associated with internal waves is much smaller than that experienced by barotropic tides, which can lead to internal waves with isopycnal displacements more than 100 times the typical surface displacement of the barotropic tides in the deep ocean. As an example, near Hawaii, internal tides have been observed with $300 \mathrm{~m}$ peak-to-peak displacements (Rudnick et al., 2003). Although there is a displacement of the free surface that propagates with internal tides, it is only in the range of centimeters. Like surface tides, internal tides generally propagate faster in deeper water. However, internal tide propagation speed also depends on how the stratification is distributed throughout the water column. If the amplitude of the internal tide is large compared to the depth of the pycnocline, then its speed 
is only a function of the stratification. Owing to the effectively shallower depth of the isopycnals at its crest, a largeamplitude internal tide may propagate more slowly at its crest than at its trough, leading to steepening of the isopycnals (Figure 1). Although all internal tides eventually steepen and lose their energy through dissipation and mixing, the most energetic and widespread internal tides appear to propagate as linear or weakly nonlinear waves. In this article, we will restrict our discussion to internal tides that do not undergo significant steepening. (Simmons et al., 2011, provide a nice introduction to nonlinear internal tides and waves).

Much of the impetus for modeling internal tides comes from the desire to understand their effects on other oceanic processes and to deepen our understanding of the tidal processes themselves. Operational oceanography, that is, ocean forecasting, is concerned with modeling internal tidal currents, which play a prominent role in shelf dynamics, particle dispersal, and other transport processes (Kurapov et al., 2003; Leichter et al., 2003; Pineda et al., 2007; Arbic et al., 2012, in this issue). Another operational concern, of particular importance to naval operations, is the influence of internal tides and waves on sound propagation (Mooers, 1973; Lynch et al., 2004; Duda et al., 2004). Internal tides are ubiquitous in ocean temperature and current meter records (Wunsch, 1975), but their details are more complicated than the barotropic tides that force them. Substantial work is directed at understanding interactions between tides and nontidal processes, such as western boundary currents (Pereira et al., 2007), near-inertial waves (Aucan

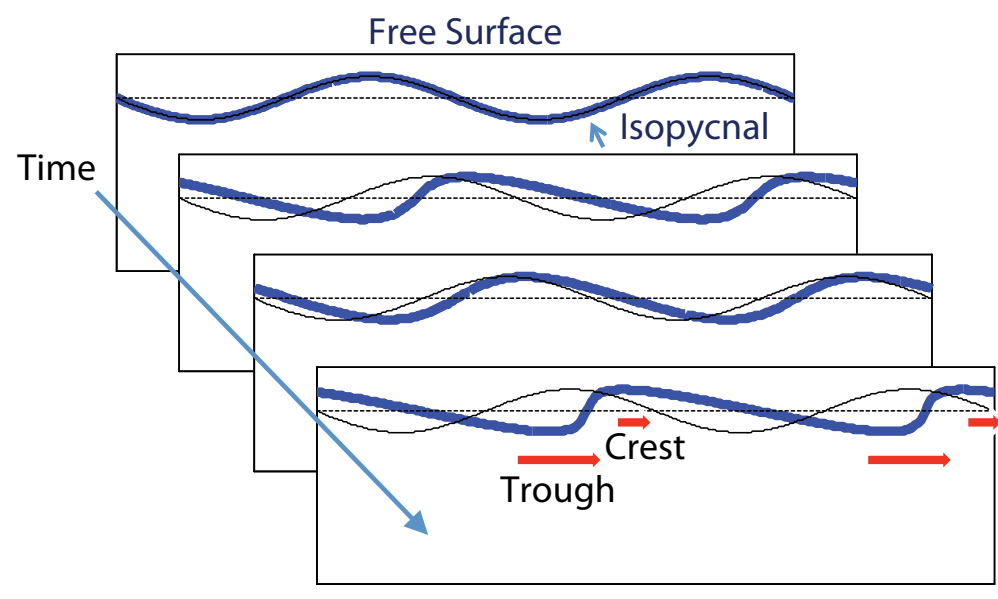

Figure 1. Propagation of an internal tide represented by the displacement of an isopycnal (thick blue line) near the free surface. The thin black line represents the initial shape and location of the wave, which, as it propagates to the right, steepens due to faster propagation of the troughs than the crests.

and Merrifield, 2008), and ocean mixing (Klymak et al., 2006). As discussed below, where the energy from tides ends up is important to our understanding of how the ocean works. Measuring the complete pathways of energy leading from the barotropic tide (scales of thousands of kilometers) to small-scale mixing and turbulent transport (scales of centimeters) is impossible to do with realistically obtainable observations. For the foreseeable future, large-scale ocean models will not be able to explicitly resolve the processes that lead to tidal dissipation, so these processes must be parameterized. Developing parameterizations that capture the spatial and temporal inhomogeneity in mixing is critical to building better global circulation models. Energy budgets in regional tidal models are a key step toward such parameterizations.

\section{NUMERICAL METHODS FOR INTERNAL TIDE SIMULATION}

Because internal tides are so long in relation to the water depth, fluid particle acceleration due to an internal tide is primarily in the horizontal and arises almost entirely from gradients in the hydrostatic pressure (which are obtained by integrating the weight of the fluid from the top of the water column downward); consequently, most internal tide models are hydrostatic. The nonhydrostatic pressure becomes important only when the horizontal scale of motion is less than the depth (Vitousek and Fringer, 2011), such as in solitarylike waves, which represent a balance between wave steepening (a hydrostatic phenomenon) and dispersion or spreading (a nonhydrostatic phenomenon).

Glenn S. Carter (gscarter@hawaii. edu) is Assistant Professor, Department of Oceanography, University of Hawaii, Honolulu, HI, USA. Oliver B. Fringer is Associate Professor, Environmental Fluid Mechanics Laboratory, Department of Civil and Environmental Engineering, Stanford University, Stanford, CA, USA. Edward D. Zaron is Research Assistant Professor, Department of Civil and Environmental Engineering, Portland State University, Portland, OR, USA. 
Nonhydrostatic models are essential for simulating processes with still shorter length scales such as overturns and turbulent eddies. In this article, we restrict our discussion to hydrostatic models, noting that most nonhydrostatic models (e.g., MIT General Circulation Model [MITgcm; Marshall et al., 1997] and Stanford Unstructured Nonhydrostatic, Terrain-following Adaptive NavierStokes Simulator [SUNTANS; Fringer et al., 2006]) are designed to run as hydrostatic models when the nonhydrostatic effects are negligible.

Among the hydrostatic models, the defining feature is the vertical coordinate system (see Figure 2). The most popular hydrostatic models used for internal tide modeling are the Princeton Ocean Model (POM; Blumberg and Mellor, 1987) and the Regional Oceanic Modeling System (ROMS; Shchepetkin and McWilliams, 2005). POM employs a sigma-coordinate system while ROMS employs a similar s-coordinate. In these coordinate systems, the grid lines follow the free surface and bottom topography

(a) Sigma

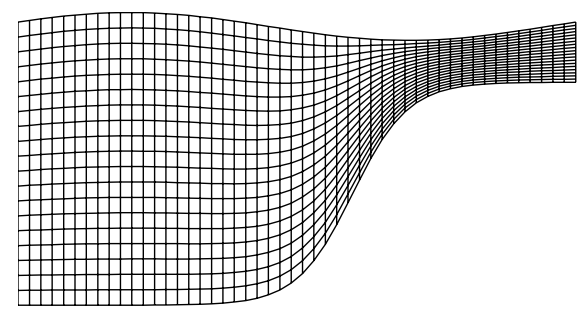

(c) Z

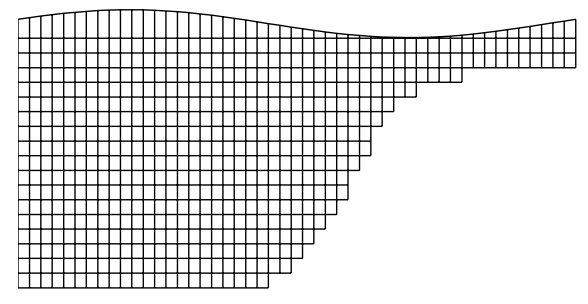

(Figure 2a,b), thereby producing good resolution of the bottom-following current that plays an important role in internal tide generation. The sigma lines are mapped to follow the free surface and bottom and are uniformly spaced through the water column; while the s-lines are similar, their vertical distribution can be varied. The greatest disadvantage to using sigma or $\mathrm{s}$-coordinates is the sigma-coordinate pressure-gradient error (e.g., Mellor et al., 1994). Because the sigma- or s-lines do not coincide with lines of constant density, these coordinates cannot reproduce a zero horizontal hydrostatic pressure gradient in the presence of a horizontally uniform density field and a horizontally uniform free surface. Although there should be no flow in such a case, the sigma-coordinate error produces upslope flow that can be on the same order as weak internal gravity wave currents. The magnitude of this error depends on the topographic slope. In addition to smoothing the domain, many other methods have been devised to

\section{(b) $\mathrm{S}$}



(d) Isopycnal

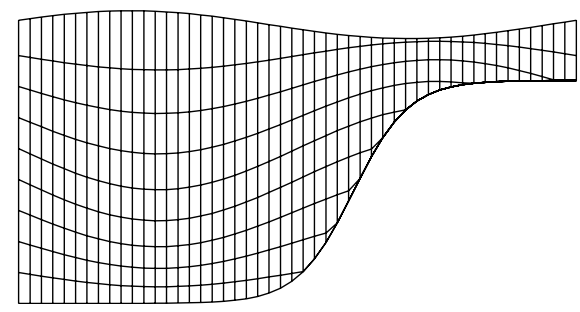

reduce this error (e.g., Shchepetkin and McWilliams, 2003). To avoid the sigmacoordinate error, it is possible to use a z-level grid, which resolves the bottom with stair or partial steps (Figure 2c). The Geophysical Fluid Dynamics LabModular Ocean Model (GFDL-MOM; Pacanowski and Gnanadesikan, 1998), MITgcm (Marshall et al., 1997), and SUNTANS (Fringer et al., 2006) are popular internal tide models that employ z-level grids. Despite the advantage of eliminating the pressure-gradient error, z-level grids have poor bottomfollowing resolution. The stairsteps tend to produce small, grid-scale internal waves that must be damped with artificial diffusion. One drawback to both z-level and bottom-following grid types is artificial damping owing to numerical diffusion when vertically oscillating isopycnals cross grid cells. This problem can be eliminated with isopycnal coordinate models that map the grid to follow the isopycnals (Figure 2d), such as the Hallberg Isopycnal Model (HIM; Hallberg and Rhines, 1996) and Miami Isopycnic Coordinate Ocean Model (ICOM; Bleck and Chassignet, 1994). Isopycnal coordinate models are best suited to global-scale internal tide modeling, which requires minimal artificial damping over long propagation distances (Simmons et al., 2004). Z-level or mapped coordinate models are better suited for coastal applications where physical mixing is desired.

Although the vertical coordinate system is the primary distinguishing feature among different internal tide models ${ }^{1}$, the most difficult aspect of internal tide

${ }^{1}$ In the horizontal, grids can be classed as rectangular, curvilinear, or unstructured. In the first two, any grid cell can be uniquely defined by two orthogonal indexes. Unstructured grids are made up of triangular elements, which allow more flexibility in changing the grid resolution within a domain.

Figure 2. Coordinate systems used in internal tide models. 
modeling is the tides' multiscale nature, both in space and in time, which makes them expensive to compute accurately. From a spatial point of view, internal tides have wavelengths as long as $250 \mathrm{~km}$ in the open ocean, but simulation of internal tide generation requires accurate representation of fine-scale topographic features with length scales of a few kilometers. This need, in turn, requires horizontal grid resolution of hundreds of meters, as shown by Jachec et al. (2007) for Monterey Bay. Hence, a domain that extends over two internal tidal wavelengths (roughly $100 \mathrm{~km}$ in a coastal domain) requires 100,000 grid points in the horizontal, or 5 million grid points in three dimensions if 50 vertical levels are employed. Due to this computational expense, internal tide modeling has begun to resolve the main features of generation in continental margins only very recently (Carter, 2010; Hall and Carter, 2011; Kang and Fringer, 2012).

The computational expense associated with the length-scale disparity between internal tide generation and propagation is exacerbated by the disparity in timescales. The shortest timescale of interest is that associated with internal tide generation. A grid resolution on the order of hundreds of meters and an internal tide speed of roughly $2 \mathrm{~m} \mathrm{~s}^{-1}$ near generation sites implies that the time needed for information to propagate across a grid cell, and hence the model time step size, must be roughly one minute to resolve the internal tide generation. At the other extreme, the simulation must be run over at least 30 days to resolve internal wave energetics associated with spring-neap variability. At the very minimum, then, a simulation with 5 million grid points must be run over 43,200 time steps to accurately resolve both the generation and the long-time energetics. Although the internal wave timescale is indeed the shortest timescale of interest, the timescale associated with the barotropic tides is typically 100 times smaller owing to the fast propagation speed of surface gravity waves. Fortunately, internal tide models do not need to explicitly resolve this short timescale. The most common method of handling the short timescales is to employ mode splitting, which was made popular by the POM model (Blumberg and Mellor, 1987). Mode splitting advances the free-surface equations in time using a so-called external mode time step size that is 100 times smaller than the internal mode time step that advances the governing equations for the internal tide. The internal tidal motions are essentially frozen in time over the course of the high-frequency, free-surface calculation, a reasonable approximation given the slowly varying nature of the internal tides relative to the fast free-surface gravity waves. The advantage of mode splitting is that the free-surface equation is two dimensional and, therefore, is computationally less expensive to advance forward in time than the three-dimensional equations for the internal tides. The main disadvantage to mode splitting is the mismatch in the depth-averaged flow between the internal tide equations and the barotropic equations, which can lead to mass and energy conservation errors if not corrected at each time step. The most popular alternative to mode splitting that does not exhibit the depthaveraged inconsistency is implicit time stepping, whereby the surface and internal tides are advanced forward in time using the time step dictated by the internal tidal motions. Implicit time stepping essentially filters out the high-frequency barotropic motions through an inverse of a two-dimensional matrix for the free surface at each time step (e.g., MITgcm and SUNTANS).

\section{MODELING BAROTROPIC AND BAROCLINIC TIDES}

When high-resolution bathymetry, realistic stratification, and accurate barotropic tidal boundary conditions are used, regional tidal models make highly accurate predictions of sea surface height $(\mathrm{SSH})$ at the dominant tidal frequencies, approaching the accuracy with which tides can be measured in the open ocean (Carter et al., 2008; Zaron et al., 2009).

Inclusion of internal tides in models can fundamentally change the SSH field compared to a barotropic model simulation. A particularly dramatic example is Monterey Bay, an approximately $40 \mathrm{~km}$ wide bay in central California. Without the inclusion of internal dynamics, the $\mathrm{M}_{2}$ tide propagates in a Kelvin-wavelike fashion up the coast, with lines of constant phase nearly perpendicular to the coastline (Figure 3a). However, observations show the $M_{2}$ tidal wave reaching Santa Cruz on the north side of the bay before reaching Monterey on the south side. Kelvin wave dynamics predict the opposite. When internal tides are included in the simulation, the phase lines within the bay run approximately north/south, and Santa Cruz leads Monterey as predicted (Figure 3b; Carter, 2010).

Simulation and validation of internal tidal currents has proved more challenging than $\mathrm{SSH}$, primarily because SSH varies smoothly over length scales of hundreds of kilometers, whereas currents associated with internal tides can vary on scales of tens of meters. Tidal currents can be represented as the sum of barotropic and baroclinic vertically standing dynamic modes. 
The higher modes have more shear and slower propagation speeds, making them increasingly susceptible to interactions with nontidal processes as mode number increases. Furthermore, due to their short length scales, internal tide currents are strongly influenced by the local topography, which is often not well reproduced in the model. Modeled and observed currents are qualitatively similar around sites of strong internal tide generation (Lee et al., 2006; Zaron et al., 2009; Chavanne et al., 2010), but the level of quantitative accuracy does not yet approach that of SSH comparisons. Interactions among tides, mesoscale features, and large-scale time-variable stratification remain the key challenge for simulation of internal tides.

\section{ENERGETICS}

It has been hypothesized that internal tides are the source of about half the energy flux through the internal wave spectrum, with wind accounting for much of the remainder (Munk and Wunsch, 1998; Wunsch and Ferarri,
2004). Consequently, the energetics of the tides have been studied intensively in order to track the work done by the astronomical tide-generating force, conversion to internal tides, and, eventually, energy lost to mixing, the latter being a source of vertical buoyancy (heat) transport in the ocean. Energy loss from the Earth-Moon system at the $\mathrm{M}_{2}$ frequency (the principal twice-daily tide; period 12.4 hours) is $2.50 \pm 0.05 \mathrm{TW}$ (Munk, 1997), a quantity that has been accurately measured by lunar laser range finding (Dickey et al., 1994) and also inferred from changes in Earth's orbit and from historical eclipses (Munk, 1997). All constituents combined put 3.7 TW of tidal energy into the ocean as barotropic tides. For comparison, the current US energy consumption is about 3.3 TW (Thresher and Musial, 2010). Inverse models constrained by satellite altimetry indicate about $1 \mathrm{TW}$ or $25-30 \%$ of barotropic tidal energy is dissipated in the deep ocean, while the remaining barotropic energy is lost directly to bottom friction in shallow
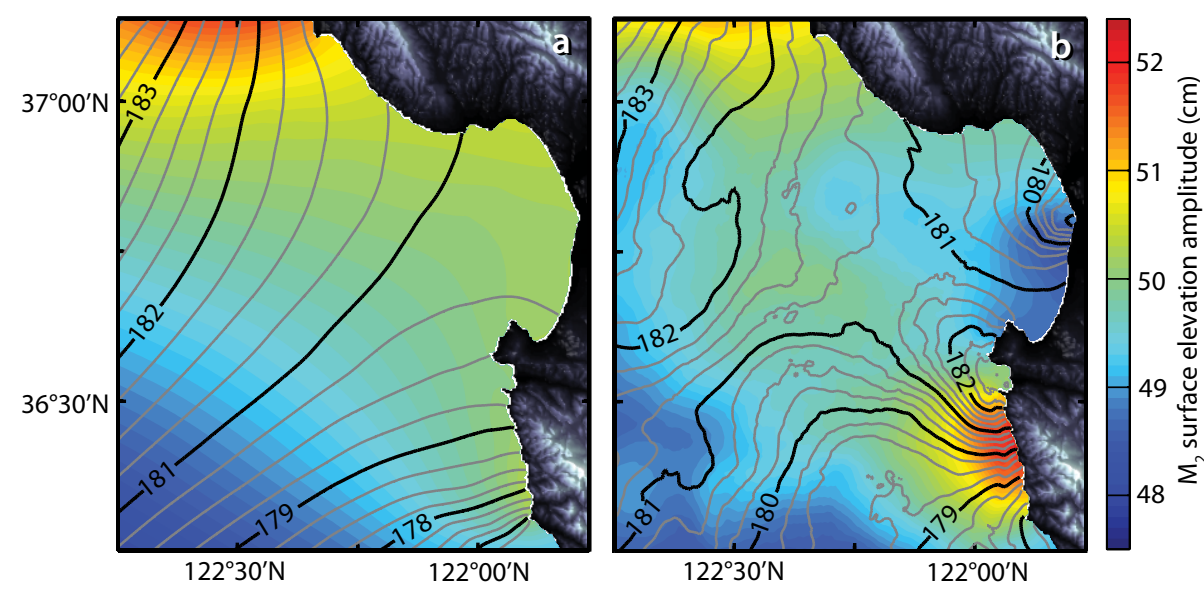

Figure 3. Cotidal plots for $\mathrm{M}_{2}$ surface elevation around Monterey Bay, California. (a) Internal tides are not permitted. (b) Internal tides are included in the model. The colors indicate the amplitude, and the contours give the phase. The black contours are spaced one degree apart, and the gray contours are every 0.25 degrees. In the absence of internal tides, the surface elevation follows Kelvin wave dynamics. When internal tides are included, both the amplitude and phase have a more complex structure. Phase lines within the bay are nearly perpendicular to those without internal tides present. Based on Carter (2010)

seas and on the continental shelf (Egbert and Ray, 2001). The barotropic energy dissipated in the deep ocean is converted into internal tides and presumably cascades through the internal wave spectrum as it propagates through the ocean, before being dissipated by viscosity.

Munk (1966) estimated that a dissipation rate of $10^{-4} \mathrm{~W} \mathrm{~kg}^{-1}$ is needed to maintain abyssal stratification; however, observed levels are 10 times smaller (Gregg, 1989; Ledwell et al., 1993). Figure 4 shows these energy pathways schematically.

Seventy-five percent of the global conversion from $\mathrm{M}_{2}$ barotropic tides into internal tides is estimated to occur over less than $10 \%$ of the ocean floor (Simmons et al., 2004). The majority of this energy is radiated out of the conversion region (St. Laurent and Garrett, 2002; Carter et al., 2008). Global models show that ocean circulation patterns (Simmons et al., 2004), and even primary productivity (Friedrich et al., 2011), are sensitive to the spatial distribution of mixing. All of this speaks to the importance of understanding the energy pathways from tides to mixing.

\section{Generation of Internal Tides}

When numerical models were first used to calculate barotropic-to-baroclinic energy conversion (internal tide generation), there were small areas with negative conversion. These values were considered "clearly not physical," and thought to provide an indication of the noise (Egbert and Ray, 2000). ${ }^{2}$ The assumption was that when conversion was calculated in higher-resolution regional models, the errors, and hence the negative conversion, would decrease. If anything, the opposite turned out to

${ }^{2}$ Egbert and Ray (2000) calculated divergence of barotropic tidal energy flux, which can be considered a proxy for internal tide generation. 
be the case; in many regional models, both the percentage of the domain with negative conversion and the magnitude relative to the positive conversion has increased (e.g., Hall and Carter, 2011; Kang and Fringer, 2012). This is more pronounced in models of regions with complex topography than in those with more isolated ridges (compare Hall and Carter, 2011, with Carter et al., 2008).

The mechanism by which internal tides are generated is briefly discussed above. More formally, the magnitude of the energy conversion from barotropic to baroclinic is the product of the vertical velocity at the bottom with the pressure anomaly averaged over a wave period (Niwa and Hibiya, 2001; Kurapov et al., 2003; Zilberman et al., 2009; Kelly and Nash, 2010) $c=\left\langle\left. w_{b} \cdot p^{\prime}\right|_{-H}\right\rangle$, where $w_{b}=\vec{U} \cdot \nabla(-H)$ is the barotropic vertical velocity at the bottom caused by barotropic current $(\vec{U})$ flowing over sloping topography;

$p^{\prime}=\int_{z}^{0} N^{2}\left(z^{\prime}\right) \varsigma\left(z^{\prime}\right) d z^{\prime}-$ $\frac{1}{H} \int_{-H}^{0} \int_{z}^{0} N^{2}\left(z^{\prime}\right) \varsigma\left(z^{\prime}\right) d z^{\prime} d z$

is the perturbation pressure, $N^{2}(z)$ is the buoyancy frequency, $\varsigma(z)$ is the vertical displacement of isopycnals, and the angle brackets indicate an average over a wave period. Following Zilberman et al. (2009), the conversion written in terms of the amplitude and phase of a single tidal constituent, say $\mathrm{M}_{2}$, is $c=\frac{1}{2}\left|w_{b} \| \hat{p}^{\prime}\right| \cos \left(\phi_{p}-\phi_{w}\right)$ where $\hat{p}^{\prime}$ is the pressure perturbation at the bottom.

From this formulation, it is clear that if the perturbation pressure and the barotropic vertical velocity are between $90^{\circ}$ and $270^{\circ}$ out of phase, the conversion will be negative. Kelly and Nash (2010) showed that both $w_{b}$ and $p^{\prime}$ have local and remote contributions.

The influence of remote generation poses a number of challenges for the regional numerical modeling of internal tides. Most apparent, the domain needs to be large enough to include the relevant remote generation sites. Hall and Carter (2011) found that excluding some outlying seamounts from a Monterey Bay simulation reduced the generation in the area common to the two simulations by $13 \%$. In the future, regional internal tide models may need to be forced with global models that resolve internal tides (e.g., Simmons et al., 2004; Arbic et al., 2012, in this issue) or nested in larger regional models (e.g., Buijsman et al., 2012).

Observations indicate nonstationary conversion rates and energy fluxes that are ascribed to a combination of propagation and generation site effects (e.g., Martini et al., 2011; Zilberman et al., 2011). Explicit inclusion of realistic mesoscales in regional models permits diagnosis of the processes and quantification of variability (Figure 5), and preliminary results find mean

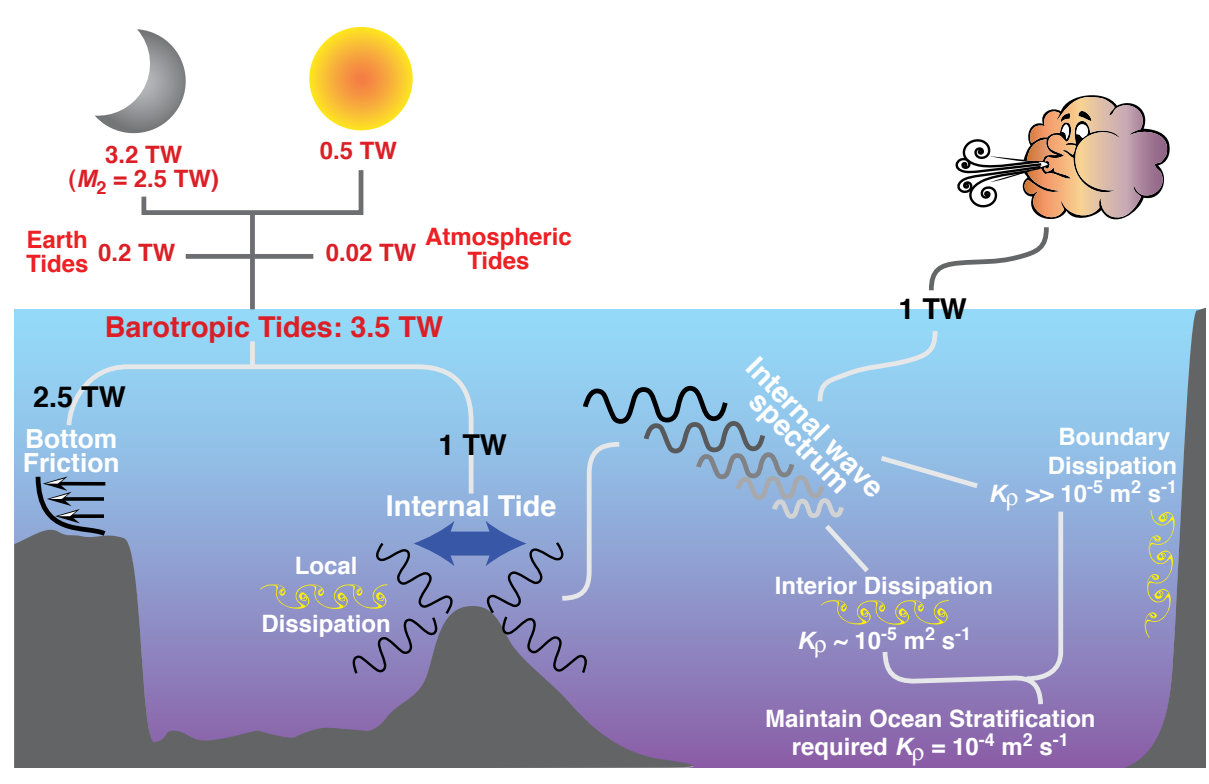

Figure 4. Energy pathway schematic (see text for details). Astronomical forcing generates tides primarily in the ocean, but also in the atmosphere and solid Earth. Over two-thirds of barotropic tidal energy is lost to bottom friction in shallow seas. Approximately $1 \mathrm{TW}$ is converted to baroclinic tides in the deep ocean; most of that energy enters the internal-wave-driven energy cascade from large scales to mixing scales. The wind provides about half the energy into the internal wave spectrum. Internal wave breaking at boundaries can short circuit the internal wave spectrum. and time-variable energy fluxes on the same scale as observations, but quantitative agreement at the level seen for SSH is not obtained.

The proportion of internal tide energy that radiates away from the generation region (i.e., is not dissipated locally) depends on the topography type; isolated ridges such as the Hawaiian Ridge are more efficient radiators than more complex bathymetry such as the Mid-Atlantic Ridge (Carter et al., 2008; Zilberman et al., 2009). Also, the modal content (distribution among vertically standing dynamic modes) varies with generation topography (Garrett and Kunze, 2007). Modeling studies show that internal tides often propagate into the deep ocean in beam-like patterns that result from interference of internal waves generated by multiple sites (Rainville et al., 2010). The higher modes have more shear and slower propagation speeds, which results

\section{Dissipation of Internal Tides}


in these modes dissipating close to the generation site (St. Laurent and Nash, 2004), as well as increased opportunity for interactions with mesoscale currents. The lowest modes can travel thousands of kilometers, as observed with acoustic tomography (Dushaw et al., 1995) and satellite altimetry (Ray and Mitchum, 1996). How these lowest internal tide modes are eventually dissipated, and contribute to the ocean energy budget, is still not well understood. Garrett and Kunze (2007) suggest the following three pathways: wave-wave interaction, scattering into higher modes over deep ocean bottom topography such as seamounts, and scattering by coastal/continental slopes. So far, little work on nonlinear wave-wave interactions has involved regional models.

Scattering off bottom topography is a good candidate for extracting energy from the low-mode internal tides, as they propagate thousands of kilometers across the abyssal ocean. It has been estimated that on the Pacific Plate, there are close to one million seamounts, with over 100,000 having heights of one kilometer or more (Wessel et al., 2010). The mechanism for scattering is very similar to that for generation, except the energy going into the higher modes comes from the low modes. Johnston and Merrifield (2003) considered a mode-1 wave impinging on a Gaussian ridge, and they found that the height of the ridge governed the proportion of reflected versus transmitted energy, while the slope and width controlled the range of vertical modes generated. Johnston et al. (2003) investigated scattering of mode-1 internal tide energy off the Line Islands Ridge, which is in

\section{Ensemble Mean Energy Flux $\left(\mathrm{kW} \mathrm{m}^{-1}\right)$}

0

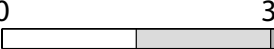

3

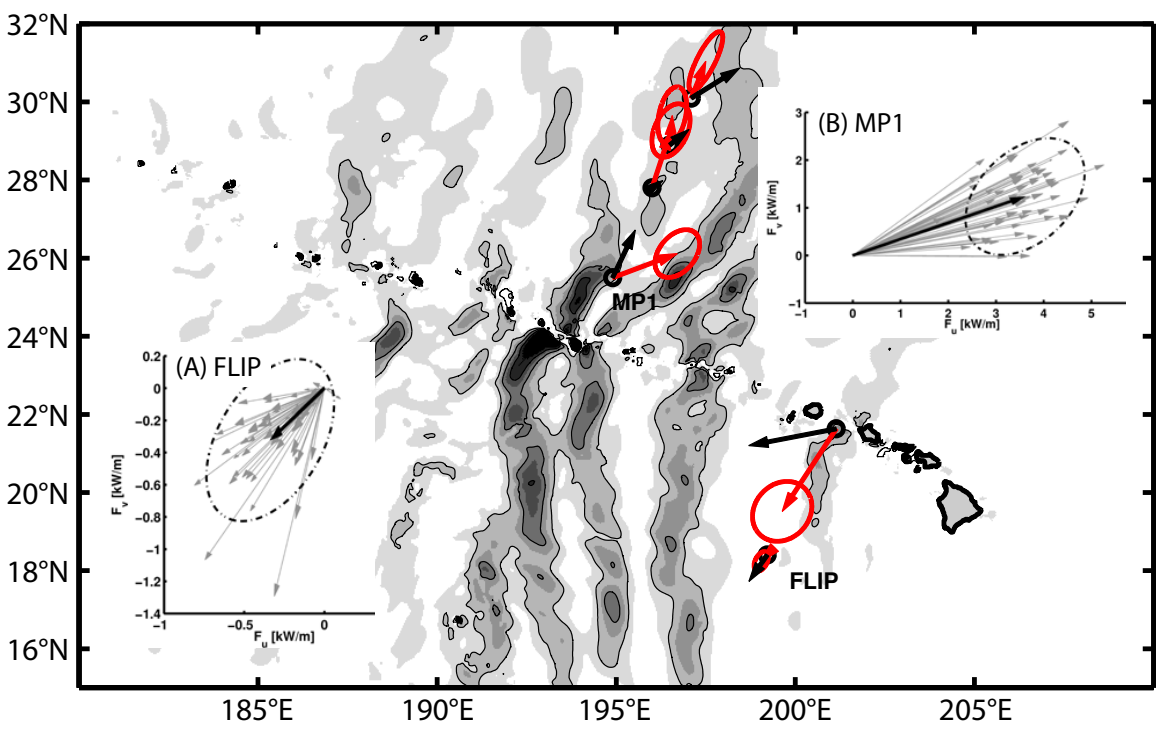

Figure 5. Time-averaged internal tide energy flux near the Hawaiian Ridge (gray scale), obtained by modeling internal tides propagating through the time-varying mesoscale eddy fields of the Simple Ocean Data Assimilation (SODA) ocean hindcast during the period from 1992 to 2002 (Carton and Giese, 2008). Interference between waves from multiple generation sites results in the beam-like structure of energy flux (Rainville et al., 2010). Model-based energy fluxes (red arrows; $2 \sigma$ variability ellipses in red) are of similar magnitude to in situ data (black arrows; data from Rainville and Pinkel, 2006; Alford et al., 2007; Zilberman et al. 2011). Individual realizations of the internal tide energy flux at two sites, FLIP (inset A) and MP1 (inset B), display considerable variability. the propagation path for internal tides generated at French Frigate Shoals on the Hawaiian Ridge. Their model showed that $37 \%$ of the $M_{2}$ mode- 1 energy was lost, with $19 \%$ going into modes 2 through 5, 3\% into $\mathrm{M}_{4}$, and the remaining being dissipated in the model.

When a remotely generated internal tide reaches a continental slope, it scatters energy much like it would in the deep ocean case. Again, the topographic slope, or, more accurately, the ratio $(\gamma)$ of the slope of the topographic slope to the wave characteristic, is important, where the wave characteristic is a function of frequency, stratification, and latitude. If the continental slope is critical $(\gamma \approx 1)$, and most have some portion that is critical with respect to the semidiurnal tides, then energy is lost to mixing (e.g., Nash et al., 2004). Unless there is some supercritical $(\gamma>1)$ topography on the continental shelf to reflect the internal tide back toward deeper water, all the transmitted energy has to dissipate on the shelf. Submarine canyons are the classic example of internal wave trapping and focusing (Gordon and Marshall, 1979; Hotchkiss and Wunsch, 1982). Regional models that include Monterey Submarine Canyon (e.g., Jachec et al., 2006; Carter, 2010; Hall and Carter, 2011; Kang and Fringer, 2012) show internal tide energy generated on the Sur Plateau being topographically steered into the canyon. Once in the canyon, the energy flux decreases fairly uniformly with distance up canyon despite the sharp canyon axis meanders (Hall and Carter, 2011).

Modeling the destruction of lowmode internal tides generated at mid-ocean sites (e.g., Hawaiian Ridge, Mid-Atlantic Ridge) when they impinge on a continental shelf thousands of kilometers away poses the same challenges as discussed above with respect to the 
impact of propagating waves on conversion. However, remote generation sites need not be thousands of kilometers away. The remote internal tides observed in a line of moorings on the Oregon slope were generated $\sim 300 \mathrm{~km}$ south at Mendocino Escarpment (Martini et al., 2011). Cases like this, or offshore seamounts, can be investigated with a regional model. Consider Delgada Canyon, which lies approximately $40 \mathrm{~km}$ south of, and is nearly parallel to, the Mendocino Escarpment (Figure 6a). Despite the canyon mouth being nearly perpendicular to the remotely generated energy flux vectors, Delgada Canyon traps, focuses, and dissipates some of this energy (Figure 6b).

A number of authors have used regional models to estimate tidal energetics. Earlier studies equated barotropic-to-baroclinic conversion to the flux divergence over a region bounding the generation site (Merrifield and Holloway, 2002; Di Lorenzo et al., 2006; Jachec et al., 2006). More recent work partitions energy based on a specific model's governing equations (Zaron and Egbert, 2006; Carter et al., 2008; Floor et al., 2011; Kang and Fringer, 2012). Using the energy equations developed in Carter et al. (2008) for POM, we examine the baroclinic energy budget for Delgada Canyon. Within the region shown in Figure 6a, $306 \mathrm{MW}$ is converted from the barotropic tide into internal tides primarily at the Mendocino Escarpment. Of this converted energy, $102 \mathrm{MW}$ $(33 \%)$ is radiated out of the model domain, and 62\% (189 MW) is lost to the Smagorinsky horizontal and MellorYamada vertical dissipation schemes. Zooming in on the canyon (Figure 6b), there is a net influx of baroclinic energy (8 MW), with $7 \mathrm{MW}$ being dissipated. The conversion in this region is $-2 \mathrm{MW}$, so the local conversion must be dominated by remotely generated $w_{b}$ or $p^{\prime}$. The budget does not close in either case. In the larger domain, there is not enough dissipation, and there is too much in the canyon. These errors may be caused by numerical viscosity, the computational mode splitting technique (Simmons et al., 2004; Zaron and Egbert, 2006), or by the use of a linear definition for available potential energy (Kang and Fringer, 2010, 2012).

\section{SUMMARY}

Regional models have proven to be important tools in increasing our understanding of internal tide dynamics. Recent successes include determining

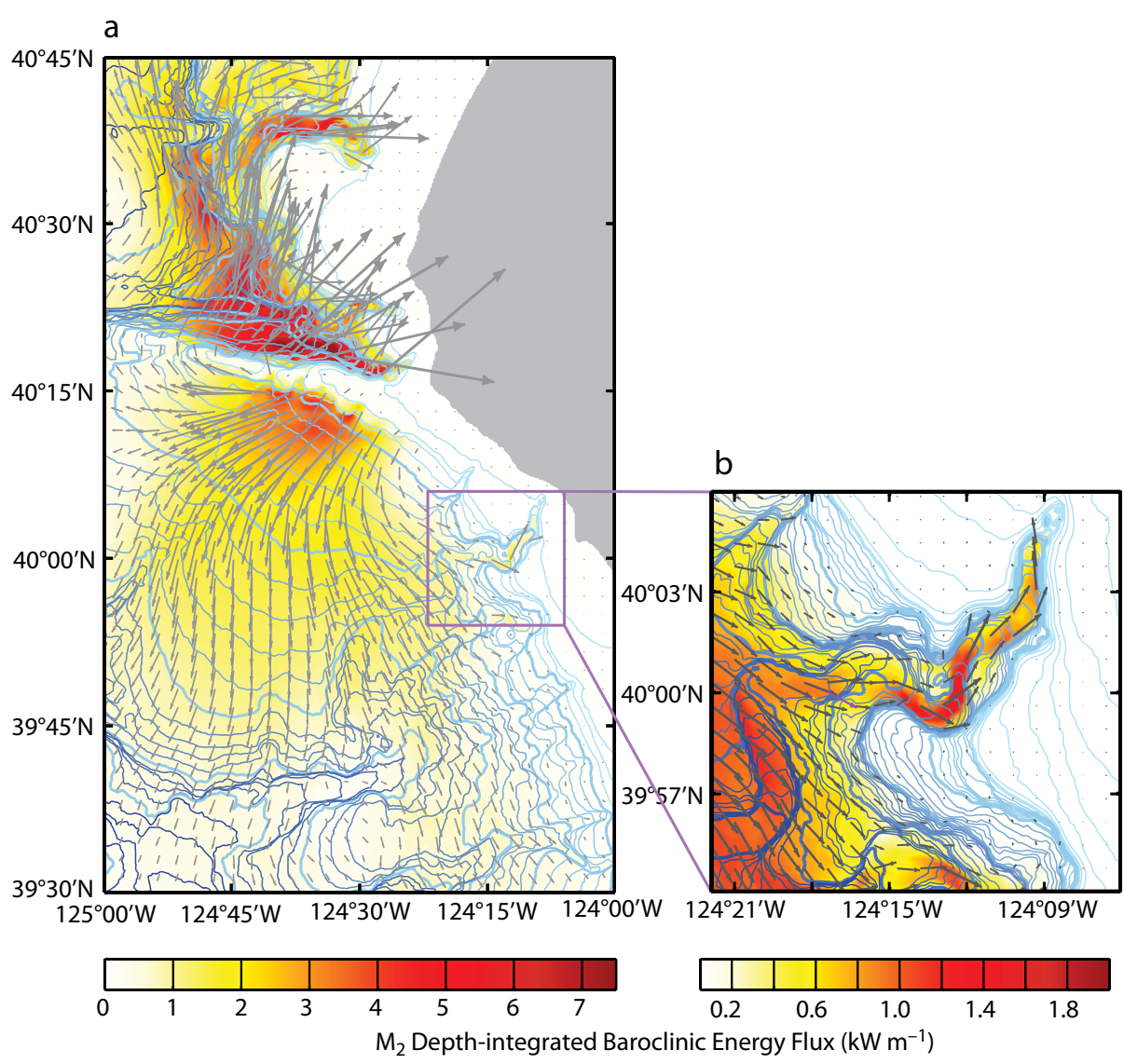

Figure 6. (a) Depth-integrated $M_{2}$ baroclinic energy flux generated at the inshore end of the Mendocino Escarpment. Colors are the flux magnitude. Bathymetry contours are at $100 \mathrm{~m}$ intervals, with thicker lines (and color changes) every 500 m. (b) A zoom in on Delgada Canyon showing along-shore flux in deeper water and on-shore flux in the canyon. The contour interval is $25 \mathrm{~m}$, with thicker lines and color changes every $200 \mathrm{~m}$. The solitary purple vector $\left(40^{\circ} \mathrm{N}\right.$, $124^{\circ} 17.4^{\prime} \mathrm{W}$ ) is an observation made in February 2009. the location and magnitude of generation regions (e.g., for Monterey Submarine Canyon, Jachec et al., 2006; Carter, 2010), identifying standing waves (e.g., Martini et al., 2007; Buijsman et al., 2012), and describing horizontal interference patterns (Rainville et al., 2010). They are useful for putting observations into a larger context (e.g., Carter et al., 2006). A final reminder: numerical models (regional or global) are approximations of reality and, therefore, need to be validated against observations.

\section{ACKNOWLEDGEMENTS}

The authors thank Matthew Alford for providing the CTD data used to initialize the Delgada Canyon model and the flux 
observation. Glenn Carter was supported by NSF-OCE grant 0751226 . Oliver

Fringer gratefully acknowledges support from the Office of Naval Research under grants N000140510294, N000141010521, and N000140810904. Ed Zaron acknowledges support from NSF-OCE grant 0623540 and NASA-OSTST grant NNX09AF20G. The authors thank two anonymous reviewers.

\section{REFERENCES}

Alford, M.H., J.A. MacKinnon, Z. Zhao, R. Pinkel, J. Klymak, and T. Peacock. 2007. Internal waves across the Pacific. Geophysical Research Letters 34, L24601, http://dx.doi.org/ 10.1029/2007GL031566.

Arbic, B.K., J.G. Richman, J.F. Shriver, P.G. Timko, E.J. Metzger, and A.J. Wallcraft. 2012. Global modeling of internal tides within an eddying ocean general circulation model. Oceanography 25(2):20-29, http://dx.doi.org/ 10.5670/oceanog.2012.38.

Aucan, J., and M.A. Merrifield. 2008. Boundary mixing associated with tidal and nearinertial internal waves. Journal of Physical Oceanography 38(6):1,238-1,252, http:// dx.doi.org/10.1175/2007JPO3718.1.

Bleck, R., and E.P. Chassignet. 1994. Simulating the oceanic circulation with isopycniccoordinate models. Pp. 17-39 in The Oceans: Physical-Chemical Dynamics and Human Impact. S.K. Majumdar, E.W. Miller, G.S. Forbes, R.F. Schmalz, and A.A. Panah, eds, The Pennsylvania Academy of Science.

Blumberg, A.F., and G.L. Mellor. 1987. A description of a three-dimensional coastal ocean circulation model. Pp. 1-16 in Three-Dimensional Coastal Ocean Models, Coastal and Estuarine Sciences, vol. 4. N.S. Heaps, ed., American Geophysical Union, Washington, DC, http:// dx.doi.org/10.1029/CO004p0001.

Buijsman, M.C., Y. Uchiyama, J.C. McWilliams, and C.R. Hill-Lindsay. 2012. Modeling semidiurnal internal tide variability in the Southern California Bight. Journal of Physical Oceanography 42(1):62-77, http://dx.doi.org/ 10.1175/2011JPO4597.1.

Carter, G.S. 2010. Barotropic and baroclinic $M_{2}$ tides in the Monterey Bay region. Journal of Physical Oceanography 40(8):1,766-1,783, http://dx.doi.org/10.1175/2010JPO4274.1.

Carter, G.S., M.C. Gregg, and M.A. Merrifield. 2006. Flow and mixing around a small seamount on Kaena Ridge, Hawaii. Journal of Physical Oceanography 36(6):1,036-1,052, http://dx.doi.org/10.1175/JPO2924.1.

Carter, G.S., M.A. Merrifield, J.M. Becker, K. Katsumata, M.C. Gregg, D.S. Luther, M.D. Levine, T.J. Boyd, and Y.L. Firing. 2008. Energetics of $M_{2}$ barotropic-to-baroclinic tidal conversion at the Hawaiian Islands. Journal of Physical Oceanography 38(10):2,205-2,223, http://dx.doi.org/10.1175/2008JPO3860.1.

Carton, J.A., and B.S. Giese. 2008. A reanalysis of ocean climate using simple ocean data assimilation (SODA). Monthly Weather Review 136:2,999-3,017, http://dx.doi.org/ 10.1175/2007MWR1978.1.

Chavanne, C., P. Flament, G.S. Carter, M.A. Merrifield, D. Luther, E. Zaron, and K.-W. Gurgel. 2010. The surface expression of semidiurnal internal tides near a strong source at Hawaii. Part I: Observations and numerical predictions. Journal of Physical Oceanography 40(6):1,155-1,179, http:// dx.doi.org/10.1175/2010JPO4222.1.

Di Lorenzo, E., W.R. Young, and S. Llewellyn Smith. 2006. Numerical and analytical estimates of $M_{2}$ tidal conversion at steep oceanic ridges. Journal of Physical Oceanography 36(6):1,072-1,084, http:// dx.doi.org/10.1175/JPO2880.1.

Dickey, J.O., P.L. Bender, J.E. Faller, X.X. Newhall, R.L. Ricklefs, J.G. Ries, P.J. Shelus, C. Veillet, A.L. Whipple, J.R. Wiant, and others. 1994. Lunar laser ranging: A continuing legacy of the Apollo Program. Science 265(5171):482-490, http://dx.doi.org/10.1126/science.265.5171.482.

Duda, T.F., J.F. Lynch, J.D. Irish, R.C. Beardsley, S.R. Ramp, C.-S. Chiu, T.-Y. Tang, and Y.-J. Yang. 2004. Internal tide and nonlinear internal wave behavior at the continental slope in the northern South China Sea. IEEE Journal of Oceanic Engineering 29:1,105-1,130, http:// dx.doi.org/10.1109/JOE.2004.836998.

Dushaw, B.D., B.M. Howe, B.D. Cornuelle, P.F. Worcester, and D.S. Luther. 1995. Barotropic and baroclinic tides in the central North Pacific Ocean determined from long-range reciprocal acoustic transmissions. Journal of Physical Oceanography 25(4):631-647, http://dx.doi.org/ 10.1175/1520-0485(1995)025<0631:BABTIT> 2.0.CO;2.

Egbert, G.D., and R.D. Ray. 2000. Significant dissipation of tidal energy in the deep ocean inferred from satellite altimeter data. Nature 405:775-778, http:// dx.doi.org/10.1038/35015531.

Egbert, G.D., and R.D. Ray. 2001. Estimates of $\mathrm{M}_{2}$ tidal energy dissipation from TOPEX/ Poseidon altimeter data. Journal of Geophysical Research 106(C10):22,475-22,502, http:// dx.doi.org/10.1029/2000JC000699.

Floor, J.W., F. Auclair, and P. Marsaleix. 2011. Energy transfers in internal tide generation, propagation and dissipation in the deep ocean. Ocean Modelling 38:22-40, http://dx.doi.org/ 10.1016/j.ocemod.2011.01.009.

Friedrich, T., A. Timmermann, T. Decloedt, D.S. Luther, and A. Mouchet. 2011. The effect of topography-enhanced diapycnal mixing on ocean and atmospheric circulation and marine biogeochemistry. Ocean Modelling 39:262-274, http://dx.doi.org/ 10.1016/j.ocemod.2011.04.012.

Fringer, O.B., M. Gerritsen, and R.L. Street. 2006. An unstructured-grid, finite-volume, nonhydrostatic, parallel coastal-ocean simulator. Ocean Modelling 14:139-278, http:// dx.doi.org/10.1016/j.ocemod.2006.03.006.
Garrett, C., and E. Kunze. 2007. Internal tide generation in the deep ocean. Annual Review of Fluid Mechanics 39:57-87, http://dx.doi.org/ 10.1146/annurev.fluid.39.050905.110227.

Gordon, R.L., and N.F. Marshall. 1979. Submarine canyons: Internal wave traps? Geophysical Research Letters 3:622-624, http://dx.doi.org/ 10.1029/GL003i010p00622.

Gregg, M.C. 1989. Scaling turbulent dissipation in the thermocline. Journal of Geophysical Research 94(C7):9,686-9,698, http://dx.doi.org/ 10.1029/JC094iC07p09686.

Hall, R.A., and G.S. Carter. 2011. Internal tides in Monterey Submarine Canyon. Journal of Physical Oceanography 41(1):186-204, http:// dx.doi.org/10.1175/2010JPO4471.1.

Hallberg, R.W., and P.B. Rhines. 1996. Buoyancy-driven circulation in an ocean basin with isopycnals intersecting the sloping boundary. Journal of Physical Oceanography 26(6):913-940, http:// dx.doi.org/10.1175/1520-0485(1996)026 $<0913$ :BDCIAO>2.0.CO;2.

Hotchkiss, F.S., and C. Wunsch. 1982. Internal waves in Hudson Canyon with possible geological implications. Deep Sea Research 29(4):415-442, http://dx.doi.org/ 10.1016/0198-0149(82)90068-1.

Jachec, S.M., O.B. Fringer, M.G. Gerritsen, and R.L. Street. 2006. Numerical simulation of internal tides and the resulting energetics within Monterey Bay and the surrounding area. Geophysical Research Letters 33, L12605, http:// dx.doi.org/10.1029/2006GL026314.

Jachec, S.M., O.B. Fringer, M.G. Gerritsen, and R.L. Street. 2007. Effects of grid resolution on the simulation of internal tides. International Journal of Offshore and Polar Engineering 17(2):105-111.

Johnston, T.M.S., and M.A. Merrifield. 2003. Internal tide scattering at seamounts, ridges, and islands. Journal of Geophysical Research 108(C6), 3180, http://dx.doi.org/ 10.1029/2002JC001528.

Johnston, T.M.S., M.A. Merrifield, and P.E. Holloway. 2003. Internal tide scattering at the Line Islands. Journal of Geophysical Research 108(C11), 3365, http://dx.doi.org/ 10.1029/2003JC001844.

Kang, D., and O.B. Fringer. 2010. On the calculation of available potential energy in internal wave fields. Journal of Physical Oceanography 40:2,539-2,545, http:// dx.doi.org/10.1175/2010JPO4497.1.

Kang, D., and O.B. Fringer. 2012. Energetics of barotropic and baroclinic tides in the Monterey Bay area. Journal of Physical Oceanography 42(2):272-290, http:// dx.doi.org/10.1175/JPO-D-11-039.1.

Kelly, S.M., and J.D. Nash. 2010. Internal-tide generation and destruction by shoaling internal tides. Geophysical Research Letters 37, L23611, http://dx.doi.org/10.1029/2010GL045598.

Klymak, J.M., J.M. Moum, J.D. Nash, E. Kunze, J.B. Girton, G.S. Carter, C.M. Lee, T.B. Sanford, and M.C. Gregg. 2006. An estimate of tidal energy lost to turbulence at the Hawaiian Ridge. Journal of Physical Oceanography 36(6):1,148-1,164, http:// dx.doi.org/10.1175/JPO2885.1. 
Kurapov, A.L., G.D. Egbert, J.S. Allen, R.N. Miller, S.Y. Erofeeva, and P.M. Kosro. 2003. The $M_{2}$ internal tide off Oregon: Inferences from data assimilation. Journal of Physical Oceanography 33:1,733-1,757.

Ledwell, J.R., A.J. Watson, and C.S. Law. 1993. Evidence for slow mixing across the pycnocline from an open-ocean tracer-release experiment. Nature 364:701-703, http://dx.doi.org/ 10.1038/364701a0.

Lee, C.M., E. Kunze, T.B. Sanford, J.D. Nash, M.A. Merrifield, and P.E. Holloway. 2006. Internal tides and turbulence along the 3000-m isobath of the Hawaiian Ridge with model comparisons. Journal of Physical Oceanography 36:1,165-1,183, http:// dx.doi.org/10.1175/JPO2886.1.

Leichter, J.J., H.L. Stewart, and S.L. Miller. 2003. Episodic nutrient transport to Florida coral reefs. Limnology and Oceanography 48:1,394-1,407.

Lynch, J.F., S.R. Ramp, C.-S. Chiu, T.Y. Tang, Y.-J. Yang, and J.A. Simmen. 2004. Research highlights from the Asian Seas International Acoustics Experiment in the South China Sea. IEEE Journal of Oceanic Engineering 29:1,067-1,074, http:// dx.doi.org/10.1109/JOE.2005.843162.

Marshall, J., A. Adcroft, C. Hill, L. Perelman, and C. Heisey. 1997. A finite- volume, incompressible Navier Stokes model for studies of the ocean on parallel computers. Journal of Geophysical Research 102(C3):5,753-5,766.

Martini, K.I., M.H. Alford, E. Kunze, S.M. Kelly, and J.D. Nash. 2011. Observations of internal tides on the Oregon continental slope. Journal of Physical Oceanography 41(9):1,772-1,794, http://dx.doi.org/10.1175/2011JPO4581.1.

Martini, K.I., M.H. Alford, J. Nash, E. Kunze, and M.A. Merrifield. 2007. Diagnosing a partly standing internal wave in Mamala Bay, Oahu. Geophysical Research Letters 34, L17604, http:// dx.doi.org/10.1029/2007GL029749.

Mellor, G.L., T. Ezer, and L.Y. Oey. 1994. The pressure gradient conundrum of sigma coordinate ocean models. Journal of Atmospheric and Oceanic Technology 11:1,126-1,134, http:// dx.doi.org/10.1175/1520-0426(1994)011 $<1126$ :TPGCOS>2.0.CO;2.

Merrifield, M.A., and P.E. Holloway. 2002. Model estimates of $\mathrm{M}_{2}$ internal tide energetics at the Hawaiian Ridge. Journal of Geophysical Research 107, 3179, http://dx.doi.org/ 10.1029/2001JC000996.

Mooers, C.N.K. 1973. Sound speed perturbations due to internal tides. Journal of the Acoustical Society America 53(1):333, http://dx.doi.org/ 10.1121/1.1982376.

Munk, W.H., 1966. Abyssal recipes. Deep Sea Research 13:707-730.

Munk, W.H., 1997. Once again: Once again-tidal friction. Progress in Oceanography 40:7-35, http://dx.doi.org/ 10.1016/S0079-6611(97)00021-9.

Munk, W., and C. Wunsch. 1998. Abyssal recipes II: Energetics of tidal and wind mixing. Deep Sea Research Part I 45:1,977-2,010, http:// dx.doi.org/10.1016/S0967-0637(98)00070-3.
Nash, J.D., E. Kunze, J.M. Toole, and R.W. Schmit. 2004. Internal tide reflection and turbulent mixing on the continental slope. Journal of Physical Oceanography 34:1,117-1,134, http://dx.doi.org/ 10.1175/1520-0485(2004)034<1117:ITRATM> 2.0.CO;2.

Niwa, Y., and T. Hibiya. 2001. Numerical study of the spatial distribution of the $\mathrm{M}_{2}$ internal tide in the Pacific Ocean. Journal of Geophysical Research 106(C10):22,441-22,449, http:// dx.doi.org/10.1029/2000JC000770.

Pacanowski, R.C., and A. Gnanadesikan. 1998. Transient response in a Z-level ocean model that resolves topography with partial cells. Monthly Weather Review 126(12):3,248-3,270, http://dx.doi.org/ 10.1175/1520-0493(1998)126<3248:TRIAZL> 2.0.CO;2.

Pereira, A.F., B.M. Castro, L. Calado, and I.C.A. da Silveira. 2007. Numerical simulation of $\mathrm{M}_{2}$ internal tides in the South Brazil Bight and their interaction with the Brazil Current. Journal of Geophysical Research 112, C04009, http://dx.doi.org/10.1029/2006JC003673.

Pineda, J., J.A. Hare, and S. Sponaugle. 2007. Larval transport and dispersal in the coastal ocean and consequences for population connectivity. Oceanography 20(3):22-39, http://dx.doi.org/ 10.5670/oceanog.2007.27.

Rainville, L., T.M.S. Johnston, G.S. Carter, M.A. Merrifield, R. Pinkel, P.F. Worcester, and B.D. Dushaw. 2010. Interference pattern and propagation of the $M_{2}$ internal tide south of the Hawaiian Ridge. Journal of Physical Oceanography 40:311-325, http://dx.doi.org/ 10.1175/2009JPO4256.1.

Rainville, L., and R. Pinkel. 2006. Propagation of low-mode internal waves through the ocean. Journal of Physical Oceanography 36:1,220-1,236, http:// dx.doi.org/10.1175/JPO2889.1.

Ray, R.D., and G.T. Mitchum. 1996. Surface manifestation of internal tides generated near Hawaii. Geophysical Research Letters 23(16):2,101-2,104, http:// dx.doi.org/10.1029/96GL02050.

Rudnick, D.L., T.J. Boyd, R.E. Brainard, G.S. Carter, G.D. Egbert, M.C. Gregg, P.E. Holloway, J.M. Klymak, E. Kunze, C.M. Lee, and others. 2003. From tides to mixing along the Hawaiian Ridge. Science 301:355-357, http://dx.doi.org/ $10.1126 /$ science. 1085837 .

Shchepetkin, A.F. and J. McWilliams. 2003. A method for computing horizontal pressuregradient force in an oceanic model with a non-aligned vertical coordinate. Journal of Geophysical Research 108, 3090, http:// dx.doi.org/10.1029/2001JC001047.

Shchepetkin, A.F., and J.C. McWilliams. 2005. The Regional Ocean Modeling System (ROMS): A split-explicit, free-surface, topography following coordinates ocean model. Ocean Modelling 9:347-404, http://dx.doi.org/ 10.1016/j.ocemod.2004.08.002.

Simmons, H.L., M.-H. Chang, Y.-T. Chang, S.-Y. Chao, O.B. Fringer, C.R. Jackson, and D.S. Ko. 2011. Modeling and prediction of internal waves in the South China Sea. Oceanography 24(4):88-99, http:// dx.doi.org/10.5670/oceanog.2011.97.
Simmons, H.L., R.W. Hallberg, and B.K. Arbic. 2004. Internal wave generation in a global baroclinic tide model. Deep-Sea Research Part II 51:3,043-3,068, http://dx.doi.org/ 10.1016/j.dsr2.2004.09.015.

St. Laurent, L., and C. Garrett. 2002. The role of internal tides in mixing the deep ocean. Journal of Physical Oceanography 32(10):2,882-2,899, http://dx.doi.org/10.1175/1520-0485(2002)032 $<2882$ :TROITI $>2.0$.CO;2.

St. Laurent, L.C., and J.D. Nash. 2004. An examination of the radiative and dissipative properties of deep ocean internal tides. Deep Sea Research Part II 51:3,029-3,042, http://dx.doi.org/ 10.1016/j.dsr2.2004.09.008.

Thresher, R., and W. Musial. 2010. Ocean renewable energy's potential role in supplying future electrical energy needs. Oceanography 23(2):16-21, http:// dx.doi.org/10.5670/oceanog.2010.39.

Vitousek, S., and O.B. Fringer. 2011. Physical vs. numerical dispersion in nonhydrostatic ocean modeling. Ocean Modelling 40(1):72-86, http:// dx.doi.org/10.1016/j.ocemod.2011.07.002

Wessel, P., D.T. Sandwell, and S.-S. Kim. 2010. The global seamount census. Oceanography 23(1):24-33, http:// dx.doi.org/10.5670/oceanog.2010.60.

Wunsch, C. 1975. Internal tides in the ocean. Reviews of Geophysics 13(1):167-182, http:// dx.doi.org/10.1029/RG013i001p00167.

Wunsch, C., and R. Ferrari. 2004. Vertical mixing, energy, and the general circulation of the oceans. Annual Review of Fluid Mechanics 36:281-314, http://dx.doi.org/ 10.1146/annurev.fluid.36.050802.122121.

Zaron, E.D., C. Chavanne, G.D. Egbert, and P. Flament. 2009. Baroclinic tidal generation in the Kauai Channel inferred from high-frequency radio Doppler current meters. Dynamics of Atmospheres and Oceans 48:93-120, http://dx.doi.org/10.1016/ j.dynatmoce.2009.03.002.

Zaron, E.D., and G.D. Egbert. 2006. Verification studies for a $\mathrm{z}$-coordinate primitive-equation model: Tidal conversion at a mid-ocean ridge. Ocean Modelling 14:257-278, http://dx.doi.org/ 10.1016/j.ocemod.2006.05.007.

Zilberman, N.V., J.M. Becker, M.A. Merrifield, and G.S. Carter. 2009. Model estimates of $M_{2}$ internal tide generation over MidAtlantic Ridge topography. Journal of Physical Oceanography 39:2,635-2,651, http:// dx.doi.org/10.1175/2008JPO4136.1.

Zilberman, N.V., M.A. Merrifield, G.S. Carter, D.S. Luther, M.D. Levine, and T.J. Boyd. 2011. Incoherent nature of M2 internal tides at the Hawaiian Ridge. Journal of Physical Oceanography 41:2,021-2036, http:// dx.doi.org/10.1175/JPO-D-10-05009.1. 